\title{
PERCEPÇÕES SOBRE GRAFFITI: ARTE OU VANDALISMO?*
}

Giulia Soster Caminha*

\begin{abstract}
RESUM0: 0 propósito deste trabalho é apresentar e discutir uma proposta de atividade didática que abarcou duas possibilidades: 0 Letramento Crítico e a pesquisa. Como proposta de Letramento Crítico, foi desenvolvida uma sequência didática utilizando como tema o graffiti para além da dicotomia percebida como arte ou vandalismo por três alunas do Curso de Extensão da Faculdade de Letras da UFMG. Para alcançar os objetivos da pesquisa de paradigma qualitativo, foram realizadas entrevistas estruturadas com as participantes sobre suas percepções e conflitos em relação ao tema da atividade didática proposta em forma de debate. A partir da discussão dos resultados foi levantado um questionamento: "Como 0 graffiti pode servir como agente transformador na vida desses alunos a fim de empoderá-los a partir da sala de aula? "A princípio a pesquisa foi pensada para alunos do curso de extensão da Faculdade de Letras (FALE/UFMG) e pretende-se estendê-la para a rede pública de ensino tendo como produto final uma oficina de graffiti e demais considerações relativas à área da linguística aplicada.
\end{abstract}

PALAVRAS-CHAVE: Letramento crítico; Ensino de inglês; Graffiti; Linguística aplicada.

\section{PERCEPTIONS ON GRAFFITI: IS IT ART OR VANDALISM?}

ABSTRACT: A didactic activity with two possibilities, Critical Literacy and Research, is discussed. In the case of Critical Literacy, a didactic sequence was developed on the theme graffiti beyond the dichotomy art or vandalism, perceived by three undergraduates of the Extension Course of the Language and Literature Faculty of UFMG. Structured interviews were prepared with the participants on perception and conflicts on didactic activity, with debates so that the aims of the qualitative paradigm research could be reached. Results of the discussion triggered the question: How may graffiti be a transforming agent in the students' life to empower them as from the classroom? Research has been prepared for students of the Extension Course of the Language and Literature Faculty of (FALE/UFMG), but may be extended to students of government-run schools. A graffiti workshop, coupled to other themes related to Applied Linguistics, is aimed at.

KEYWORDS: Critical literacy; teaching of English; Graffiti; Applied linguistics.

\section{INTRODUÇÃO}

0 graffiti faz parte da sociedade e é o componente visual da cultura do hip-hop (LIMA; SILVA, 2004) que representa e também configura um meio de resistência de uma cultura oprimida por discursos massificados. Androutsopoulos (2003 apud PENNYCO0K, 2007, p. 103) argumenta que "hip-hop é uma rede global dispersa de práticas culturais diárias que são produtivamente apropriadas em diferentes contextos, pode ser vista como uma dialética paradigmática e uma globalização cultural e ao mesmo tempo local". Em outras palavras, como um elemento visual de uma cultura própria, podemos inferir que o graffiti é a representação de uma identidade em uma abordagem autêntica que usa a arte para indagar questões culturais e de insatisfação.

0 objetivo principal deste artigo é investigar as percepções, conflitos e preferências de três alunas do curso de extensão da Faculdade de Letras (FALE/UFMG) e, desta forma, apresentar às participantes, um

\footnotetext{
Este artigo é uma versão expandida do trabalho de Iniciação Científica, realizado na Faculdade de Letras (FALE) da Universidade Federal de Minas Gerais (UFMG), sob a orientação da Professora Dra. Andréa Machado de Almeida Mattos

${ }^{* *}$ Graduanda em Letras/Inglês pela Universidade Federal de Minas Gerais. Docente na Faculdade de Letras CENEX/FALE. Participa do Grupo de Pesquisa em Estudos Críticos sobre Linguagens, Letramentos e Educação, registrado no CNPq, Brasil. E-mail: giulia_soster@hotmail.com
} 
panorama sobre a origem do graffiti, seus precursores, conceitos, diferenças entre graffiti e pichação e suas demais modalidades.

Em vista disso, este artigo valeu-se do graffiti como prática social com o propósito de desenvolver, em sala de aula de língua inglesa, uma proposta educacional sobre letramento crítico a ser aplicada no cenário de ensino de línguas estrangeiras no Brasil após a publicação das Orientações Curriculares para o Ensino Médio (BRASIL, 2006) e hoje tem sido amplamente utilizado tanto para pesquisas quanto para o desenvolvimento de atividades de sala de aula (SOARES, 2014). Assim, para alcançar os objetivos deste artigo, como veremos, foi desenvolvida uma sequência didática, utilizando como tema 0 graffiti como forma de reexistência (SILVA, 2009).

\section{METODOLOGIA}

A partir dos objetivos e das definições teóricas estabelecidas para este artigo optou-se por utilizar a abordagem de investigação qualitativa, visto que esta pode possuir uma perspectiva de estudo de caso (TELLES, 2002). 0 paradigma de pesquisa escolhido para esse artigo, somado à proposta de letramento crítico, deu-se então para verificar a opinião das alunas entrevistadas a partir da investigação em sala de aula por meio da atividade-debate pretendida para esse trabalho ${ }^{3}$.

0 tema deste artigo surgiu a partir de uma aula de inglês sobre graffiti. A princípio, o tema e suas vertentes foram expostos a dez alunos para que ficassem familiarizados com 0 assunto. A partir dessa aula, foi proposta uma atividade-debate acerca da proposição: graffiti como arte ou vandalismo?. A turma foi dividida em dois grupos, um grupo defenderia graffiti como arte e o outro como vandalismo. Para

\footnotetext{
3 Por se tratar de pesquisa com seres humanos, seu projeto original foi submetido à avaliação do COEP por meio de sua vinculação ao projeto principal intitulado "Letramentos e Ensino de Inglês como Língua Estrangeira", que tem como investigadora principal a Professora Dra. Andréa Machado de Almeida Mattos e obteve aprovação em 19/05/2015, sob o número 420990315.5.0000.5149
}

o debate valer-se de forma mais concisa, foram apresentados argumentos para que ambos os grupos se fundamentassem para 0 desenvolvimento de sua própria argumentação.

Adiante a atividade e para uma realização mais completa da pesquisa que aqui é relatada, foram entrevistadas três alunas do curso de extensão da Faculdade de Letras (FALE/UFMG) a fim de questionálas sobre suas preferências e considerações em relação ao graffiti. No início das entrevistas, foi questionado se elas já possuíam algum conhecimento sobre 0 assunto e, após o desenvolvimento da conversa, se consideravam o tema de cunho crítico e o por quê. Essas entrevistas foram gravadas e posteriormente transcritas para análise.

As perguntas são tangentes ao que é o graffiti, se as alunas sabem a diferença entre graffitie pichação, se conhecem o trabalho de algum grafiteiro(a), sobre a opinião do tema trabalhado em forma de debate dentro da sala de aula, se desenvolveram alguma habilidade da língua inglesa durante a atividade e, por fim, quais eram suas preferências dentro do ensino crítico.

Foi adotado como procedimento ético um questionário de consentimento para essa pesquisa devidamente autorizado pelas alunas, que foram informadas que poderiam abster-se a qualquer momento. Para a condução desse trabalho, a preservação da identidade das participantes foi de suma importância, portanto foram usados nomes fictícios.

\subsection{CARACTERÍSTICAS DO GRAFFITI}

0 hip-hop teve origem em meados de 1970 em Nova lorque (SIMÕES, 2013, p. 107), sendo 0 graffiti considerado 0 elemento visual dessa cultura. Após um movimento artístico de pintar grandes muros, conhecido por muralismo, começou a surgir alguns elementos mais ligados ao graffiti contemporâneo "enquanto expressão artística e humana" (GITAHY, 1999, p. 16).

Diferente do muralismo, o graffiti tem como 
suporte as ruas, viadutos etc, além de grandes murais como é mais conhecido. Gitahy (1999) argumenta que existem dois tipos de características que fazem parte da linguagem do graffiti que seriam aspectos estéticos e conceituais. "A estética seria a expressão plástica figurativa e abstrata; utilização do traço e/ou da massa para definição de formas; natureza gráfica e pictórica; repetição de um mesmo estilo quando feito a mão livre" (p. 17). 0 graffiti, segundo Gitahy (1999), tem como natureza conceitual o fato de ser

Subversivo, espontâneo, gratuito e
efêmero; discute e denuncia valores
sociais, políticos e econômicos com
muito humor e ironia; apropria-se
do espaço urbano a fim de discutir,
recriar, e imprimir a interferência
humana na arquitetura da metrópole;
democratiza e desburocratiza a arte,
aproximando-a do homem, sem
distinção de raça ou de credo; produz
em espaço aberto sua galeria urbana
pois os espaços fechados dos museus
e afins são quase sempre inacessíveis.
(p. 18).

Como pode ser observado, nas características conceituais do graffiti, 0 ato de grafitar interfere em esferas públicas e privadas da cidade. Pode ser feito tanto num muro com autorização e receber um feedback positivo, dependendo do que foi pintado, ou até mesmo num muro residencial sem autorização, que seria a modalidade do graffiti vandal (GITAHY, 1999). 0 próprio nome da modalidade se refere ao ato como algo depreciativo, que infringe leis e normas na sociedade, sendo um dos pontos em que o graffiti é considerado transgressor.

Em 1998, entrou em vigor no Brasil a lei de número 9.605 de crimes ambientais (BRASIL, 1998), que considera, em seu artigo 65, 0 ato de pichar ou grafitar sem autorização um crime punível com pena de detenção de seis meses a três anos e multa. No entanto, $02^{\circ}$ parágrafo da mesma lei diz que

$\S 2^{0}$ Não constitui crime a prática de graffiti realizada com 0 objetivo de valorizar 0 patrimônio público ou privado mediante manifestação artística, desde que consentida pelo proprietário e, quando couber, pelo locatário ou arrendatário do bem privado e, no caso de bem público, com a autorização do órgão competente e a observância das posturas municipais e das normas editadas pelos órgãos governamentais responsáveis pela preservação e conservação do patrimônio histórico e artístico nacional (Incluído pela Lei $\mathrm{n}^{0}$ 12.408, de 2011(BRASIL, 2011)).

Quando uma lei como essa entra em vigor, leva a questionar então 0 que seria afinal 0 graffiti. Por que algumas imagens são permitidas e até mesmo admiradas e outras são consideradas ato de vandalismo? De acordo com Gitahy (1999), "paradoxalmente, esse impedimento do exercício coletivo de liberdade de criação contribui para que 0 artista continue na busca da perfeição, superandose, firmando-se acima das possíveis críticas e da aceitação maior do público" (p. 36). Logo, percebemos que 0 graffiti, além de ser um ato transgressor, é também sinônimo de resistência.

Há, no entanto, uma distinção bastante clara entre graffiti e pichação. A pichação também utiliza os mesmos moldes e suporte que o graffiticom a diferença de que não encontramos figuras pictóricas e sim as assinaturas que são conhecidas por tags, privilegiando as letras (GITAHY, 1999). Como na pichação o foco é nas letras e não em formas ou imagens consideradas "bonitas", essa prática torna-se muito menos tolerada. É um ato muito mais reprimido tanto pelas pessoas comuns quanto pela polícia e pelo poder público. Segundo Gitahy (1999), "na ditadura militar quase não se viam paredes rabiscadas em São Paulo" (p. 22). Isso se deve ao fato de que, segundo 0 autor, "pichação e graffiti têm sempre algo em comum, carregam em si a transgressão e, por isso, existem em sociedades razoavelmente abertas - não combinam com ditadura" (p. 23). Em outras palavras, em países com leis mais tolerantes em relação a práticas artísticas como 0 graffiti, acabam não só por tolerar como incentivar tais condutas por meio de festivais internacionais. 
Na atualidade, apesar do graffiti ainda ser algo passível de pena criminal quando feito na modalidade vandal (GITAHY, 1999), com autorização, esses trabalhos têm ganhado cada vez mais espaço dentro do Brasil como 0 Street of Styles, festival internacional que ocorreu em Curitiba em sua oitava edição em 2018 e o Bahia de Todas as Cores Graffiti Festival que passou pela terceira edição em 2015 também reunindo notáveis artistas visuais.

\subsection{GRAFFITI COMO ELEMENTO IDENTITÁRIO E DE RESSIGNIFICAÇÃO CULTURAL}

A resistência mencionada diversas vezes tendo o graffiti como um produto, não parte apenas de práticas transgressoras, mas de uma tentativa de manter uma representatividade cultural de pessoas que sofrem uma marginalidade histórica. Silva (2009) argumenta sobre a questão da construção da identidade de um povo ou da ressignificação dessas identidades que foram oprimidas durante muito tempo por um discurso homogêneo e genérico sobre a diversidade cultural, de raça, posicionamento político etc. 0 hip-hop ou 0 graffiti como quinto elemento desse movimento, nada mais é do que uma luta por espaços que foram apropriados de forma opressora. Hall (2003, p. 338-339, apud SILVA, 2009, p. 49-50) afirma que

É nesse cenário de disputa por idéias e sentidos, em meio a projetos homogeneizantes de cultura, que 'a marginalidade' abre brechas em busca de formas de ganhar mais espaço na sociedade. Com as transformações resultantes do histórico de lutas e reivindicações em torno do direito à existência de 'diferentes diferenças', surgem novos sujeitos e são produzidas novas identidades em um fluxo marcado pelas 'guerras de posição' no cenário cultural; enfrentamentos entre setores dominantes e dominados que, sem sair de dentro do intricado jogo de relações de poder, redefinem a cultura e alteram 0 equilíbrio da hegemonia cultural.
Assim, indo além dos questionamentos de arte ou vandalismo, o graffiti é principalmente um agente transformador dentro dessa disputa de poder. É o produto visual de grande movimento de ressignificação no que tange a identidade de um grupo majoritariamente negro e em vulnerabilidade social e torna-se, então, um meio de resistência dessas vozes oprimidas e marginalizadas dentro da sociedade.

\subsubsection{Ensino crítico de língua inglesa}

0 ensino crítico de língua inglesa surgiu com a proposta de novos letramentos com 0 intuito de ajudar 0 aluno a pensar criticamente por meio de uma perspectiva comunicativa da segunda língua (MATTOS; VALÉRIO, 2010). Teve como um de seus precursores Paulo Freire (1970, apud MCLAUGHLIN; DEVO0GD, 2005) que argumenta que o intuito do ensino crítico é ver os alunos como participantes ativos dentro dos processos de desenvolvimento de uma determinada língua, mais precisamente nas habilidades de leitura e escrita. É necessário que os alunos sejam capazes de fazer inquirições acerca das relações de poder entre autor e leitor dentro do conteúdo que Ihes é apresentado.

Para além de saber ler e escrever em uma segunda língua é fundamental que os alunos consigam ler também o que não foi escrito. Que sejam capazes de indagar-se sobre as reais intenções do autor e de onde parte a perspectiva que Ihes foi exposta. Segundo McLaughlin e DeVoogd (2004), é primordial que o professor motive os alunos propondo perguntas como "de onde parte tal ponto de vista?" ou, por exemplo, "Que ação você pode tomar com base no que aprendeu?". 0 propósito é provocar 0 aluno a fim de torná-lo um participante ativo no que diz respeito ao contexto onde esses alunos estão inseridos. Mattos (2011) parte de uma perspectiva de novos letramentos e sugere estimular os alunos a fim de transformá-los em constituintes dinâmicos na sociedade, cidadãos, educandos empoderados que possam se questionar sobre seu lugar no mundo, suas identidades, relações culturais etc. 
De acordo com McLaughlin e DeVoogd (2004), existem quatro princípios que atuam como pilares dentro da perspectiva do letramento crítico: "Letramento Crítico concentra-se nas questões de poder e promove reflexão, transformação e ação; Letramento Crítico com foco no poder e suas complexidades; Dinamicidade de estratégias com viés crítico adaptáveis ao contexto no qual são usadas; Letramento Crítico como rompimento do comum por meio de diferentes perspectivas" (p. 14-16).

Em relação a "Letramento Crítico concentrase nas questões de poder e promove reflexão, transformação e ação", as autoras argumentam sobre instigar 0 aluno a inquirir de onde partiu o ponto de vista apontado no texto, ou, por que 0 autor decidiu trabalhar o tema de determinada forma, se alguma voz foi silenciada para induzir a perspectiva estabelecida no texto, entre outros aspectos que se relacionam com 0 ato de refletir sobre 0 conteúdo.

Há diversas maneiras de se trabalhar assuntos de cunho crítico dentro da sala de aula, sempre com 0 intuito de promover uma participação dinâmica do aluno e tendo como ponto principal aspectos como história, contexto e relação de poder (MCLAUGHLIN; DEVO0GD, 2005). 0 objetivo é que o professor também seja criticamente letrado e apresente uma variedade de textos, atividades, materiais autênticos, recursos tecnológicos e instigue 0 aluno a questionar tudo 0 que lhe é exposto.

Ainda que as teorias de ensino comunicativo (EC) e letramento crítico (LC) conversem, de acordo com Mattos e Valério (2010), existem algumas diferenças entre essas duas correntes. Enquanto 0 ensino comunicativo (EC) tem 0 objetivo de letrar 0 aluno a fim de contribuir para que ele possua as ferramentas necessárias para socialização, que seja capaz de trocar experiências, de argumentar a respeito de diversos assuntos, de compreender o que está em seu entorno, o letramento crítico (LC) atua como um agente de transformação na vida desse aluno. Além de compreender, 0 aluno será capaz de agir; 0 objetivo é "aprender para transformar" (p. 140) 0 meio onde está inserido.
SILVA (2009) utiliza o hip-hop somado à abordagem de multiletramentos para tratar das questões de reexistências. Além desse trabalho, há outros que também relacionam o hip- hop e o graffiti ao contexto escolar. Ramalho e Schilichta (2009), por exemplo, abordam o tema descrevendo uma intervenção feita em uma escola de educação pública com 0 intento de levar arte à escola, e Almeida (2012) relaciona 0 hip-hop e o ensino de língua inglesa na perspectiva de construção de identidades. A autora faz uma comparação entre o Black English e 0 inglês padrão por meio de músicas e aborda também manifestações do hip-hop em relação à cultura negra.

Portanto, um artigo como este, que utiliza 0 graffiti somado à proposta de letramento crítico para o ensino de língua inglesa, atua na colaboração para que os participantes, além de letrados e socializados em uma língua adicional, sejam estimulados a pensar criticamente. Bray et al (2000 apud MATEUS, 2009, p. 311) argumentam que: "a ciência pode contribuir para que as pessoas percebam seus valores, vislumbrando um futuro melhor e se organizando de modo eficaz para alcançá-lo." 0 intuito é colaborar para que as participantes da pesquisa desenvolvam suas percepções e conflitos acerca do graffiti, por meio de uma perspectiva do ensino crítico da língua inglesa.

Hall (2003, apud SILVA, 2009, p. 260) aborda a questão que perpassa 0 terreno da cultura e das tradições e atesta que é na dialética entre cultura e tradição que novos elementos surgem e "podem ser reorganizados para se articular a diferentes práticas e posições e adquirir um novo significado e relevância". Em outras palavras, novas formas e ressignificações ganham voz e representatividade por diferentes meios e 0 graffiti atua como um produto visual desse diálogo.

\section{RESULTADOS}

As análises surgem da perspectiva do ensino crítico da língua inglesa e têm como objetivo ajudar os alunos a questionarem o que lhes é apresentado, 
refletindo sobre as relações de poder, focando em problemas de cunho social e suas complexidades, além de examinar cada situação a partir de múltiplas perspectivas (MCLAUGHLIN; DEVOOGD, 2005). As entrevistas com as alunas foram transcritas e as transcrições foram analisadas em busca de respostas aos objetivos de cada pergunta.

Primeiramente o questionamento levantado foi se as alunas gostavam de graffiti e elas responderam respectivamente como mostra a transcrição:

P: Você gosta de graffit?

Joana: Gosto.

Cristina: Eu gosto, gosto. Eu gosto, não conheço mas eu gosto.

Maria: É, eu acho legal.

A partir da primeira pergunta, infere-se que as alunas de alguma forma apreciam 0 assunto, apesar de a aluna Cristina afirmar não ter tanta proximidade com o objeto de estudo. Dando sequência, as alunas foram questionadas se elas sabiam a diferença entre grafitti e pichação. Os excertos abaixo mostram as respostas de cada participante.

P: Você sabe a diferença entre graffiti e pichação?

Joana: Sei. A pichação pra mim é a questão do protesto, né? Querendo ou não ela não tem uma construção de uma imagem, de uma coisa que possa ser entendida. E já 0 graffiti sim, o graffiti tem esse construto, que é a questão de se construir uma imagem e querer trazer alguma coisa pra aquilo de visual que seja bonito ou não, o graffiti não tem tanto essa estética.

Cristina: Eu acho que eu sei, posso falar? Eu acho que o graffiti é uma arte, na minha opinião é uma arte, é uma expressão de alguém que tá querendo mostrar alguma coisa. A pichação eu penso que é uma... eu não penso que é uma arte.

Maria: Sim. Pelo que eu sei pichação é quando não é... não é um desenho, é tipo uma assinatura, tipo de gangues, mas eu não sei se existe esse termo gangues, e o graffiti é um desenho que você faz e expressa alguma coisa.

Joana, por possuir formação em artes visuais, respondeu à pergunta de forma mais elaborada em relação a suas colegas, como podemos analisar nos excertos transcritos acima. A aluna deixa clara a distinção entre o graffiti e a pichação em sua natureza conceitual e estética e compreende que ambas as modalidades são de cunho transgressivo numa tentativa de dar "voz" às minorias. Cristina e Maria responderam a pergunta com foco puramente estético. É perceptível na fala de Maria, apesar de a aluna não usar o termo "transgressão", a captura do sentido transgressor das duas práticas quando ela relaciona a pichação com a motilidade procedente de gangues, ou seja, de pessoas oriundas da marginalidade, dos guetos.

Outro questionamento levantado foi em relação à proximidade com 0 trabalho de algum grafiteiro/a. Cristina e Maria declararam não conhecer nenhum trabalho com exceção dos que foram apresentados em sala de aula. Joana, por estar ligada à área das artes, assegura que conhece alguns trabalhos como se vê no excerto a seguir:

P: Você conhece o trabalho de algum grafiteiro/a?

Joana: Conheço, tem, aqui em BH tem a Criola ${ }^{4}$, que eu gosto muito dela, ela trabalha com a questão da afrodescendência, então ela sempre pinta mulheres, faz graffiti de mulheres negras. $E$ tem alguns amigos que são grafiteiros mas não são muito conhecidos. Tem um amigo meu que chama Guilherme, mas ele não é conhecido, e ele faz trabalho assim, ele vai na escola, ensina graffiti, é mais um trabalho social, sabe? é muito legal. 
Na fala de Joana é nítida a questão da representatividade, pois, como mulher negra, a aluna reconhece 0 trabalho da grafiteira Criola como uma problematização das questões raciais. É notória também a visão da aluna em relação ao graffiti como um agente de transformação social ou representatividade cultural.

A pergunta a seguir entra no campo do ensino crítico de inglês e foi abordada a fim de investigar a relevância sobre Graffiti como tema de cunho crítico em sala de aula. A pergunta utilizada foi: "Você considera o Graffiti um tema crítico? Por quê?"

P: Você considera o graffiti um tema de cunho crítico? Por quê?

Joana: Eu acho que agora ele ta mais bem aceito, porque, quando ele começou a surgir né, no norte da américa e tal, com aquela questão da pop art, ele era visto como uma coisa ruim, do que eu tenho estudado e que eu sei né. Ele surgiu no gueto, né? Na marginalidade da população afrodescendente na américa. Basquiat $^{5}$ tem muita coisa com graffiti. Então antes ele era visto como uma coisa suja, por causa dessa, essas pessoas que faziam eram pessoas marginalizadas que queriam ser vistas, então era sujo. Hoje em dia não, hoje em dia 0 graffiti já é bem visto porque tem uma indústria, sabe? Por trás também, eu sei que ele é importante, mas ainda querendo ou não, ele é bem visto porque tem uma indústria cultural que deslocou aquilo e fez aquilo ser bonito, e mais também por causa da pop art né, foi com a pop art que ele meio que subiu assim.

Maria: Ah, eu acho que é porque, tipo, acho que toda arte tem um pouco de crítica né, mas acho que o graffiti é mais porque é nas ruas e todo mundo tem acesso, quer dizer, não todo mundo né, mas é uma coisa mais acessível então acho que talvez tenha relacionado a isso.
A análise dá-se ao fato do graffiti ser considerado crítico pela marginalidade das pessoas que praticam essa modalidade artística. Em ambos os excertos, as alunas reconhecem a prática como arte $\mathrm{e}$ destacam também as diferentes proporções artísticas em que o graffiti encontra-se atualmente, como um produto dentro da indústria cultural. Pennycook (2004) problematiza a questão da autenticidade do hip-hop como algo que aos poucos foi se ressignificando e já não segue à risca os pressupostos de sua origem pela globalização. Logo, o graffitinão existe puramente para dar voz às margens, mas também como um produto meramente contemplativo.

Por fim, a última pergunta foi em relação à perspectiva de letramento crítico e outros assuntos que partem de um pressuposto crítico em sala de aula.

P: Qual a sua opinião sobre 0 uso de assuntos de temas críticos dentro de sala de aula?

Joana: Eu acho importante, porque você tem que trazer o senso crítico e 0 raciocínio pras pessoas, independente de qualquer faixa etária, desde criança, até adulto, adolescente, pessoas mais velhas também, acho que é importante.

Cristina: Eu acho que a sala de aula é o lugar da discussão, 0 lugar do debate, eu acho que tudo, dependendo da proposta do professor, acho que tudo tem que trazer pra sala de aula, tanto do olhar do professor quanto do próprio aluno também, se ele achar interessante que vá tratar de um tema, acho que a sala de aula é um lugar da discussão mesmo.

Maria: Eu acho que devia ser mais abordado, porque por exemplo, na minha escola a gente nunca falou sobre isso, e eu achei muito legal que você trouxe pra gente, porque eu por exemplo não tenho muito contato com essas coisas.

Jean-Michel Basquiat, artista americano 
A fala das alunas salienta a importância da discussão em sala de aula. Cristina trabalha em uma escola de educação básica da rede municipal de Belo Horizonte e ressalta a importância do levantamento de tais assuntos como propostas educacionais. Sua fala destaca que para o desenvolvimento de tal perspectiva, o posicionamento do professor é de grande importância visto que seu discurso dentro de sala de aula pode tanto ajudar 0 aluno a pensar criticamente quanto manipular arbitrariamente a proposição escolhida. McLaughlin e DeVoogd (2005) ressaltam a questão da relação de poder entre autor e leitor que também pode ser interpretada na relação professor aluno quando se trata de enfatizar ou não pontos que seriam cruciais para uma discussão dentro da escola.

\section{DISCUSSÃO DOS RESULTADOS}

Para finalizar as discussões relativas à pesquisa, foi observado que todas as alunas apreciam o tema escolhido em forma de debate e prezam pela perspectiva crítica dentro do ambiente escolar/ educacional. Não obstante ao fato de algumas alunas não estarem tão familiarizadas com 0 tema, suas opiniões foram de suma importância para a realização desta investigação e para os resultados obtidos.

Como dito na seção anterior, a proposta do debate sobre graffiti como arte ou vandalismo surgiu de uma aula de inglês no curso de extensão da Faculdade de Letras (FALE/UFMG). A concepção da atividade deu-se tanto para verificar as opiniões acerca do tema do graffiti e do ensino crítico de inglês como também para usar a segunda língua dentro de um contexto que estivesse carregado de significação para as pessoas entrevistadas. Meyer (2001, apud MCLAUGHLIN; DEVOOGD, 2005, p. 25) afirma que "além de expressar uma relação de poder, a língua é histórica e só pode ser entendida com referência a seu contexto". Essa concepção histórica dentro do discurso inserido no contexto crítico parte da perspectiva interacional na abordagem "Whole language" (RICHARDS; RODGERS, 2001) que entende a língua como um sistema autêntico e essencialmente inserido na vivência dos alunos.

\section{CONCLUSÃo}

Por esse artigo valer-se do paradigma de pesquisa qualitativa, que de acordo com Mateus (2009) "se fortalece como espaço de observação da realidade" (p. 310) os objetivos previamente estabelecidos foram alcançados na medida em que se pretendia investigar as percepções das participantes da pesquisa em relação ao graffiti enquanto arte ou vandalismo. As alunas são claras quanto às suas percepções e seus conflitos sobre 0 assunto e ressaltam a relevância da sala de aula como um lugar de discussão e transformação de alunos sociáveis para cidadãos empoderados.

A participação e as contribuições das alunas participantes da pesquisa têm "a emancipação como fim último" (CELANI, 2005, p. 111) e o LC atua como principal ferramenta no que diz respeito ao empoderamento ou formação do aluno-cidadão (SOARES, 2014). Desta forma, 0 graffiti foi 0 elemento escolhido para o levantamento de todas as questões ao longo da pesquisa e a princípio pensado na dicotomia entre arte e vandalismo. No entanto, como agente de transformação podemos dizer que vai além desse diálogo e passa a ser também elemento de transformação e também de representação das causas identitárias e culturais.

Para uma investigação mais profunda, pretende-se estender esse trabalho a um projeto de mestrado da pós-graduação (Poslin/UFMG) a fim de ampliar 0 número de participantes e contribuições essenciais aos estudos da linguística aplicada. 


\section{REFERÊNCIAS}

ALMEIDA, L. Hip-hop e a formação da identidade cultural no ensino de língua inglesa. In: SIMPÓSIO NACIONAL DISCURSO, IDENTIDADE E SOCIEDADE, 3., 2012. Anais... Campinas: Unicamp, 2012.

BRASIL. Altera Art. 65 da Lei de Crimes Ambientais. Diário Oficial [da] República Federativa do Brasil. Brasília, DF, 25 maio. 2011. Disponível em: <http:// www.planalto.gov.br/ccivil_03/_ato20112014/2011/ lei/l12408.htm >. Acesso: 01 set. 2018.

BRASIL. Art. 65 da Lei de Crimes Ambientais. Diário Oficial [da] República Federativa do Brasil. Brasília, DF, 12 fev. 1998. Disponível em: <https:// www.jusbrasil.com.br/topicos/11331651/artigo-65da-lei-n-9605-de-12-de-fevereiro-de-1998>. Acesso em: 10 jan. 2018.

\section{BRASIL. Orientações curriculares para o ensino} médio: linguagens, códigos e suas tecnologiasconhecimentos de línguas estrangeiras. Brasília: Ministério da Educação; Secretaria de Educação Básica, 2006.

CELANI, M. A. A. Questões de ética na pesquisa em Linguística Aplicada. Linguagem e Ensino, Pelotas (RS), v. 8, n. 1, p. 101-122, 2004. Disponível em: <http://www.rle.ucpel.tche.br/index.php/rle/article/ view/198/165 >. Acesso em: 11 de ago. 2018

FREIRE, P. Pedagogia do oprimido. 17. ed. Rio de Janeiro: Paz e Terra, 1987.

GITAHY, C. 0 que é graffiti. São Paulo: Brasiliense, 1999.

LIMA, P; SILVA, A. Para além do Hip Hop: juventude, cidadania e movimento social. Motrivivência, n. 23, p. 61-82, 2004.

MATEUS, E. Torres de babel e línguas de fogo: um pouco sobre pesquisa na formação de professores de inglês. Rev. bras. linguist. apl. [online], v. 9, n. 1, p. 307-328, 2009. Disponível em: <http://dx.doi. org/10.1590/S1984-63982009000100015>. Acesso em: 26 nov. 2018.
MCLAUGHLIN, M.; DEVO0GD, G. L. Critical Literacy: Enhancing Students' Comprehension of Text.

Education Review//Reseñas Educativas, 2005. Disponível em: <http://edrev.asu.edu/edrev/index. php/ER/article/view/491 > Acesso em: 02 set. 2018.

MATTOS, A. M. A. Novos letramentos, ensino de língua estrangeira e o papel da escola pública no século XXI. Revista X, v. 1, p. 33-47, 2011.

MATTOS, A. M. A.; VALÉRIO, K. M. Letramento crítico e ensino comunicativo: lacunas e intersecções. RBLA, v. 10, n. 1, p. 135-158, 2010.

MCLAUGHLIN, M.; DEV00GD, G. Critical literacy as comprehension: Expanding reader response. Journal of Adolescent \& Adult Literacy, v. 48, n. 1, p. 5262, 2004.

MCLAUGHLIN, M.; DEV00GD, G. Critical Literacy: enhancing students' comprehension of text. Education Review//Reseñas Educativas, 2005. Disponível em: <http://edrev.asu.edu/edrev/index. php/ER/article/view/491 > Acesso em: 02 set. 2018.

PENNYCOOK, A. Language, localization, and the real: Hip-hop and the global spread of authenticity. Journal of Language, Identity, and Education, v. 6 , n. 2, p. 101-115, 2007.

RAMALHO, M. E.; SCHLICHTA, C. A. B. D. Graffiti na escola?. Curitiba: Paraná, 2009. Disponível: <http://www.diaadiaeducacao.pr.gov.br/portals/pde/ arquivos/1738-8.pdf> Acesso em: 4 ago. 2018.

RICHARDS, J. C.; RODGERS, T. S. Approaches and methods in language teaching. New York: Cambridge University Press, 2001.

SILVA, A. L. Letramentos de reexistência. Tese (Doutorado em Linguística Aplicada) - Instituto de Estudos da Linguagem, Unicamp, Campinas, 2009.

SIMÕES, J. A. Entre percursos e discursos identitários: etnicidade, classe e gênero na cultura hip-hop.

Revista de Estudos Feministas, Florianópolis, v. 21, n. 1, jan./abr. 2013, p. 107-128. 
SOARES, E. A. C. 0 letramento crítico no ensino de língua inglesa: identidades, práticas e percepções na formação do aluno-cidadão. Dissertação (Mestrado em Linguística Aplicada) - Poslin, UFMG, Belo Horizonte, 2014.

TELLES, J. A. É pesquisa, é? Ah, não quero, não, bem! Sobre pesquisa acadêmica e sua relação com a prática do professor de línguas. Revista Linguagem \& Ensino, v. 5, n. 2, p. 91-116, 2012. Disponível em: $<$ http://revistas.ucpel.edu.br/index.php/rle/article/ view/238>. Acesso em: 26 nov. 2018.

Recebido em: 01/10/2018

Aceito em: 22/11/2018 